\title{
Effect of Aqueous and Methanolic Extracts of Momordica charantia Fruit on Blood Glucose and Liver Enzymes in Diabetic Rats
}

\author{
Kermany H. ${ }^{1}$ MSc, Shahanipour K.* PhD, Nakhaee A.R. ${ }^{2}$ PhD \\ *Biochemistry Department, Falavarjan Branch, Islamic Azad University, Isfahan, Iran \\ 1Biochemistry Department, Falavarjan Branch, Islamic Azad University, Isfahan, Iran \\ ${ }^{2}$ Biochemistry Department, Medicine Faculty, Zahedan University of Medical Sciences, Zahedan, Iran
}

\begin{abstract}
Aims: Karela (Momordica charantia), is extensively used in traditional medicine as an antidiabetic drug. The aim of the present study was to analyze the effect of aqueous and methanolic extrarct of Momordica charantia on blood glucose and liver enzymes of rats.

Materials \& Methods: In this experimental study, 36 adult male Wistar rats were divided into 6 groups (6 rats in each group); control (healthy rats), negative control (diabetic rats by Streptozotocine) and 4 experimental groups (diabetic rats which recived aqueous and methanolic extracts of plant in concentrations of 50 and $100 \mathrm{mg} / \mathrm{kg}$ of body weight daily for 40 days). The amount of the blood glucose was determined by sequential incision of the tip of the tail once a weak. After completing 40 days, blood was collected from heart of rats and the level of the liver enzymes serum was determined. The results were analysed by ANOVA with repeated measure and one way ANOVA tests in SPSS 19 software.

Findings: The effect of different concentrations of aqueous and methanolic extracts on the blood glucose level was significant $(p<0.001)$. Also a significant difference was observed between the amount of the aspartate aminotransfrase $(p=0.049)$ and alanin aminotransfrase $(p=0.005)$ enzymes activity at the two groups of negative control and $50 \mathrm{mg} / \mathrm{kg}$ of body weight of methanolic extract. Using of 50 and $100 \mathrm{mg} / \mathrm{kg}$ of body weight of aqueous and methanolic extracts reduced the alkalin phosphatase enzyme activity ( $\mathrm{p}=0.002)$.

Conclusion: Aqueous extract of Momordica charantia fruit have better effect on reducing the blood glucose than methanolic extracts. Both aqueous and methanolic extracts reduce the activity of aspartate aminotransfrase, alanin aminotransfrase and alkalin phosphatase.
\end{abstract}

\section{Keywords}

Momordica charantia [http://www.ncbi.nlm.nih.gov/mesh/68029777];

Diabetes Mellitus [http://www.ncbi.nlm.nih.gov/mesh/68003920];

Liver [http://www.ncbi.nlm.nih.gov/mesh/68008099];

Rats [http://www.ncbi.nlm.nih.gov/mesh/68051381]

\footnotetext{
* Corresponding Author

Tel: +983117725585

Fax: +983133390000

Address: Department of Biochemistry, Islamic Azad University, Daneshgah Boulevard, Basij Boulevard, Falavarjan, Iran

shahanipur_k@yahoo.com

Received: November 30, $2014 \quad$ Accepted: May 10, 2015 ePublished: June 20, 2015
} 
مقدمه

ديابت نوعى اختلال مزمن در متابوليزم كربوهيدرات، هربى و مهن

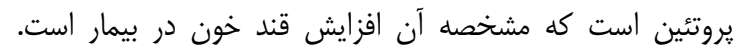
نارسايى قلبى - عروقى، كليوى و كاهش فعاليت عصبى از جمله عوارض اين بيمارى است. بيمارى ديابت بلددليل عدم جذب سلب سلولى فئى

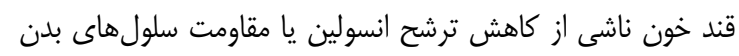

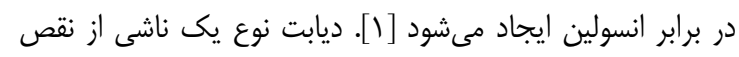

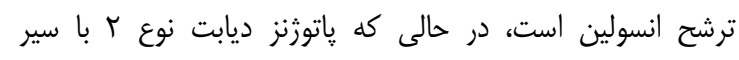

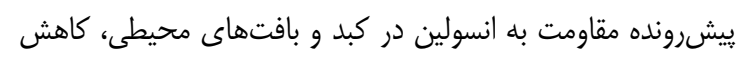

توده سلولهاى بتا و نقص ترشح انسولين همراه است [ب، بَ].

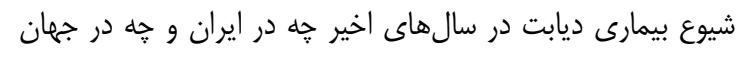

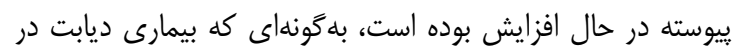

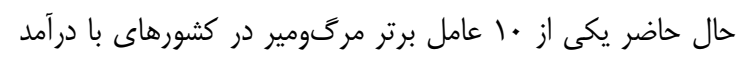
متوسط محسوب مىشود. اين در حالى است كه در كشورهاى

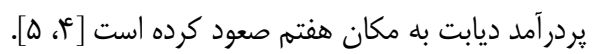

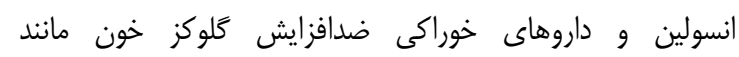

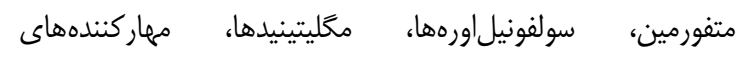

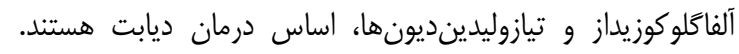

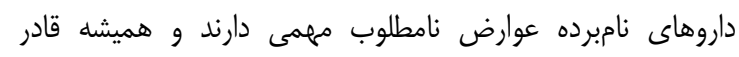

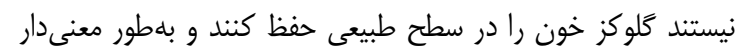

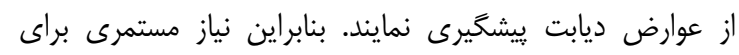

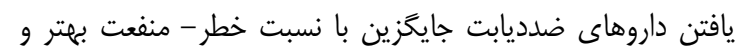

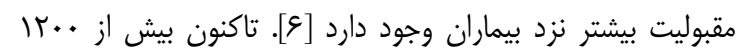

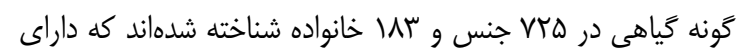

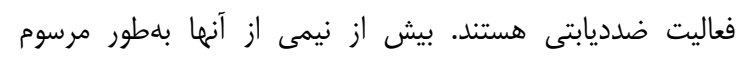

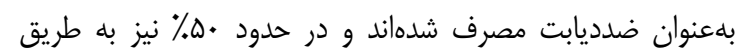
آزمايشگاهى مطالعه شدهاند [V] AST آنزيمهايى هستند كه بلهور عمده در كبد يافت مىشوند، اما در

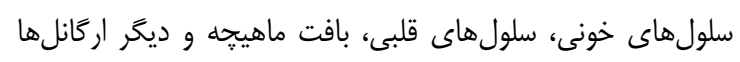

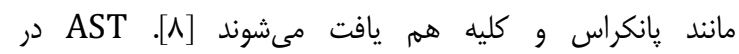

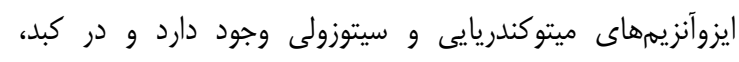

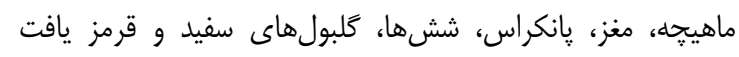

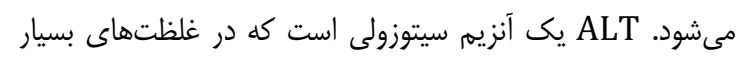

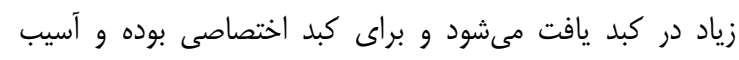

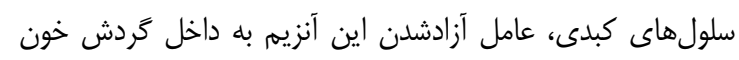

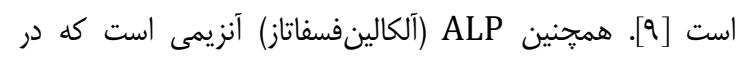
بسيارى از بافتها وجود دارد و بلممقدار زيادى از كبد و استخوان

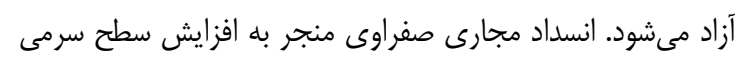
ALP

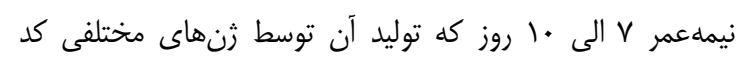

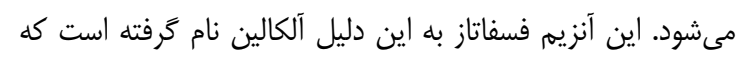

تاثير عصاره آبى و متانولى ميوه كار لا (هندوانه

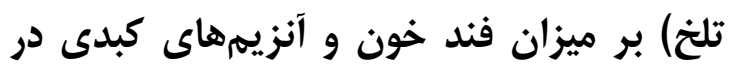
موشهاى صحر ايى ديابتى حميده كرمانى $\quad$ MSc

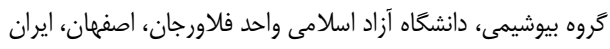
كمين شاهانى يور " PhD كروه بيوشيمى، دانشخاه آزاد اسلامى واحد فلاورجان، اصفهان، ايران عليرضا نخعى PhD كروه بيوشيمى، دانشكده يزشكى، دانشعاه علوم يزشكى زاهدان، زاهدان، ايران جكيده اهداف: كارلا (مومورديكا خارانتيا) بلهور گستردهاى در طب سنتى

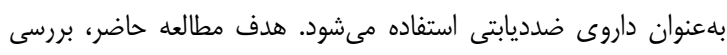

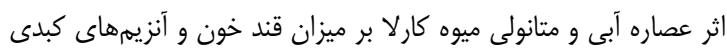
در موش صحرايى بود. مواد و روشها: در اين مطالعه تجربى، عس موش صحرايى نر بالغ نزاد

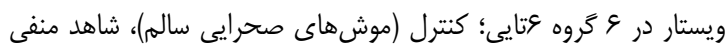

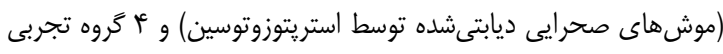

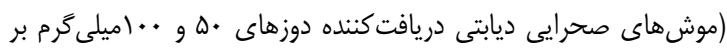

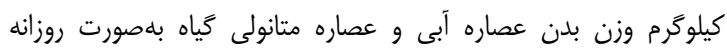

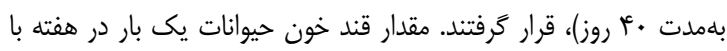

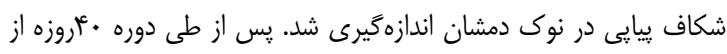

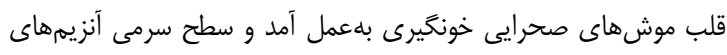

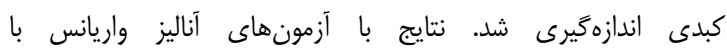
اندازهيرىهاى مكرر و آناليز واريانس يكىطرفه توسط نرمافزار

19 تحليل شدند. يافتهها: تاثير غلظتهاى مختلف تذند عصارههاى آبى و متانولى بر ميزان قند

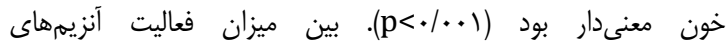

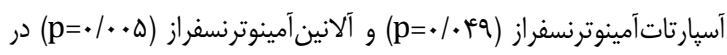

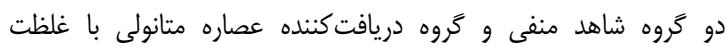

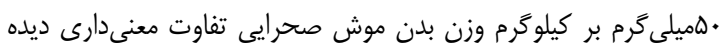

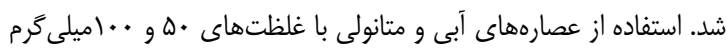

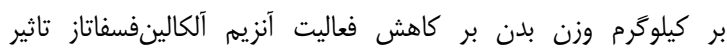

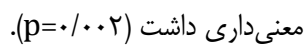

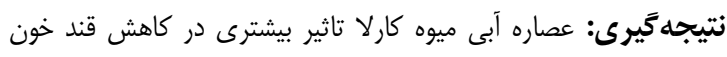

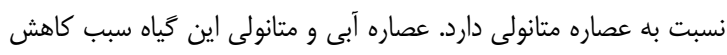

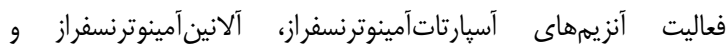
آلكالين فسفاتاز مىشود. كليدوازهها: مومورديكا هارانتيا، ديابت، آنزيمهاى كبدى، موش صحر ايى

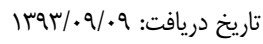

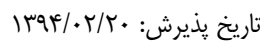
"نويسنده مسئول: shahanipur_k@yahoo.com 


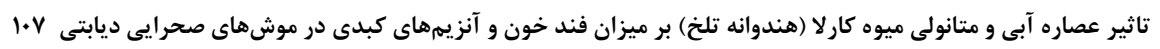

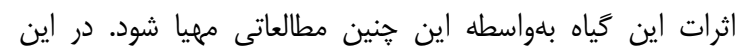

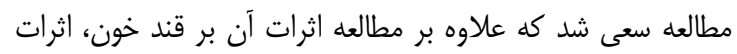

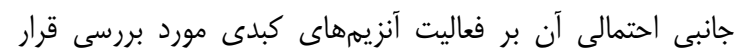
كيرد. بنابراين هدف مطالعه حاضر، تعيين خاصيت ضدديابتى عصارههاى

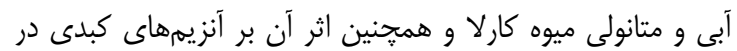

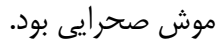

\section{مواد و روشها}

در اين مطالعه تجربى، ميوه تازه كَياه كارلا از مزارع دهستان كهير

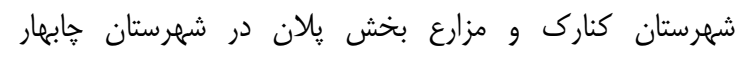

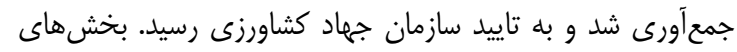

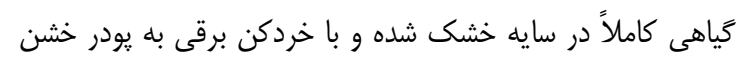

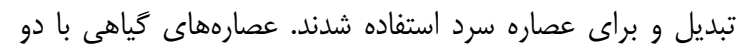

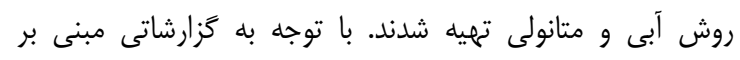

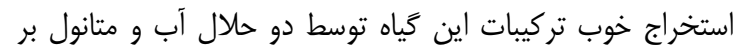

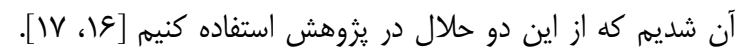

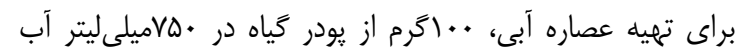

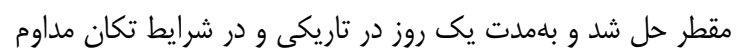

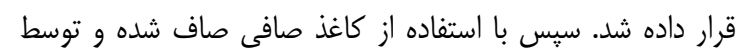

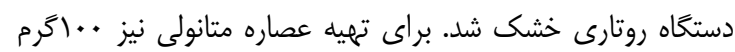

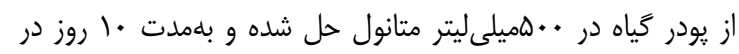

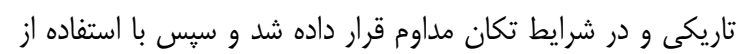

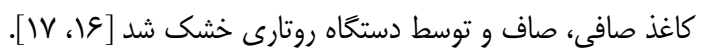

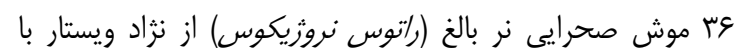

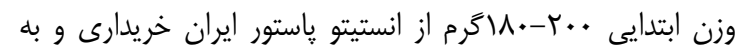

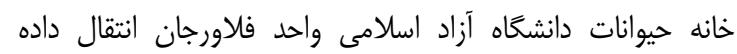

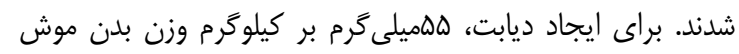

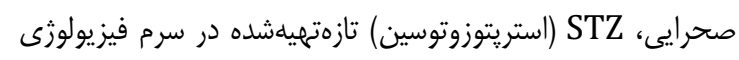

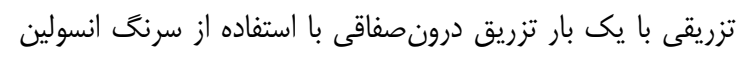

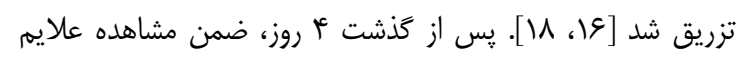

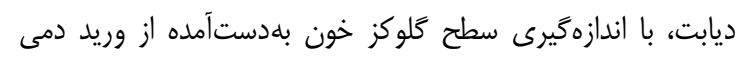

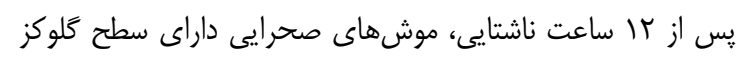

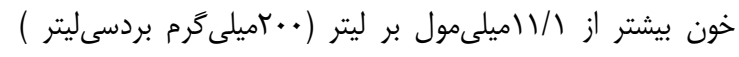

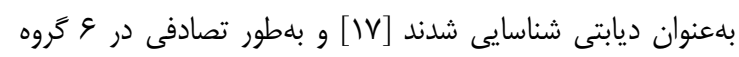

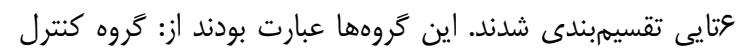

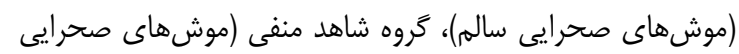

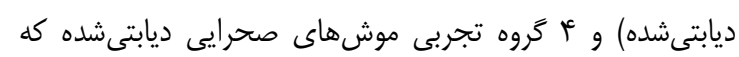

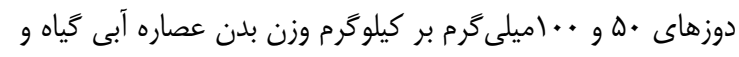

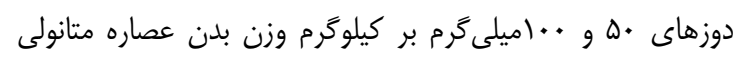

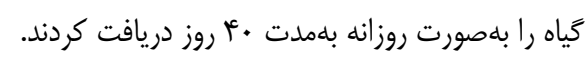

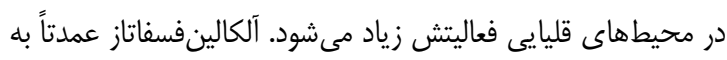

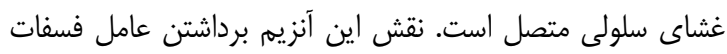

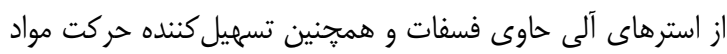

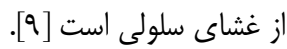

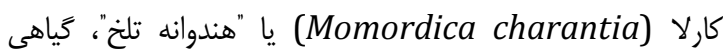

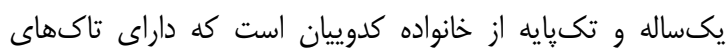

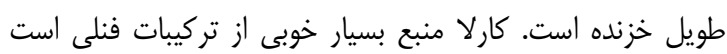

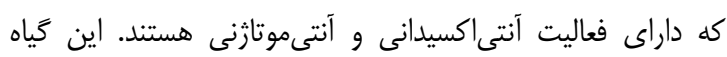

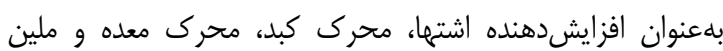

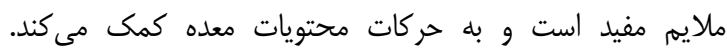

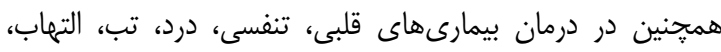

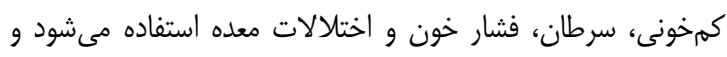

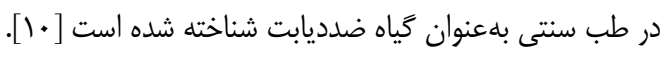

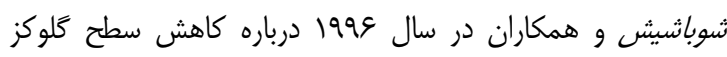

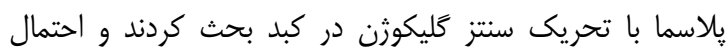

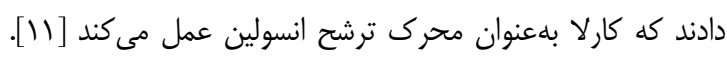

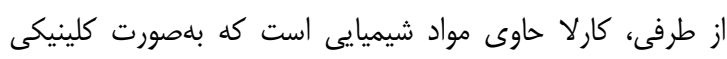

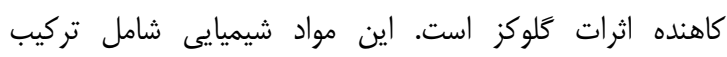

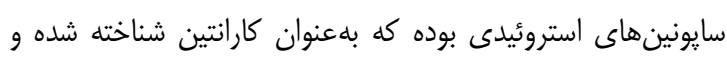

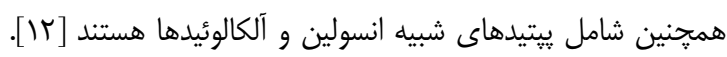

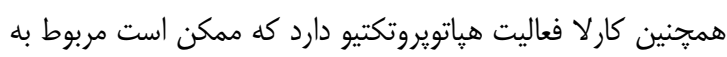

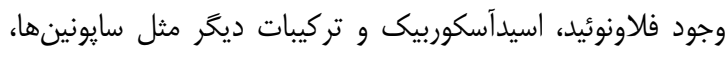

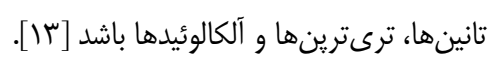

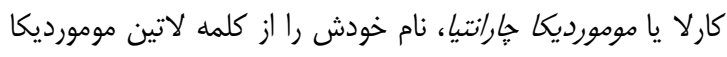

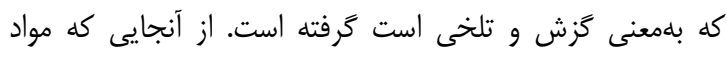

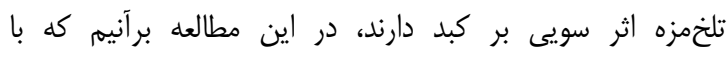

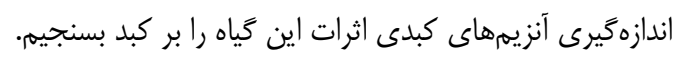

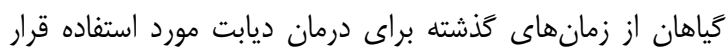

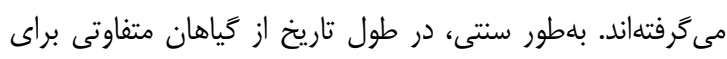

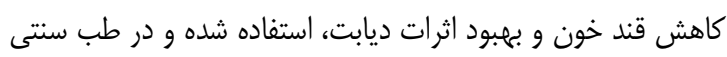

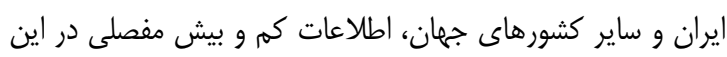

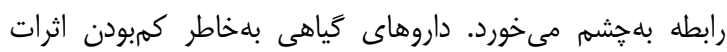

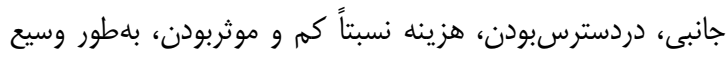

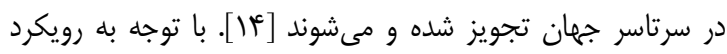

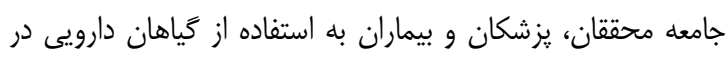

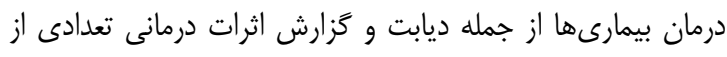

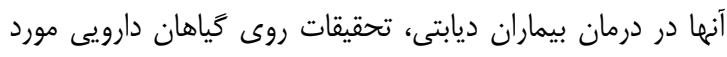

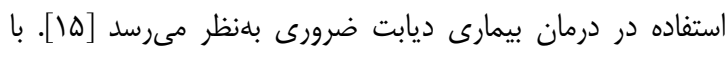

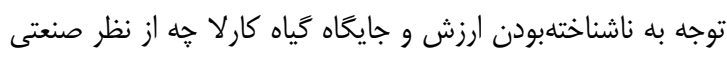

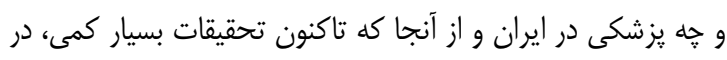

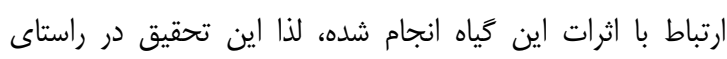

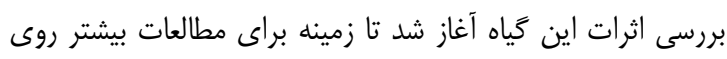




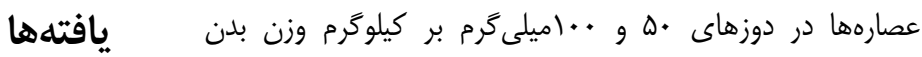
تاثير غلظتهاى مختلف عصارههاى آبى و متانولى بر ميزان قندار

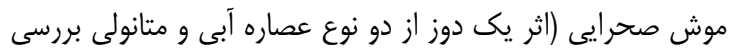

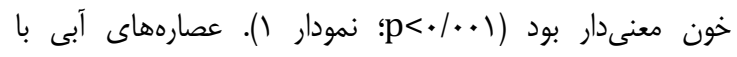

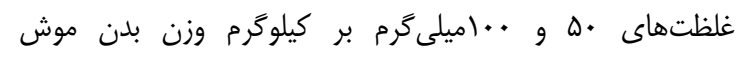

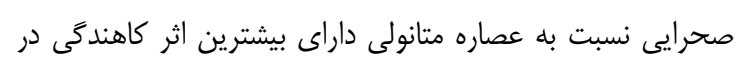

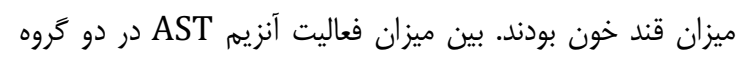

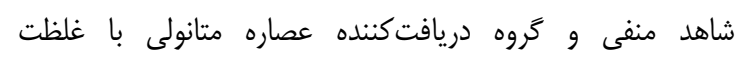

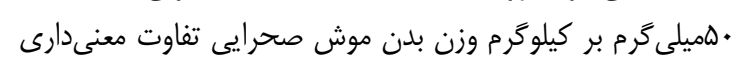

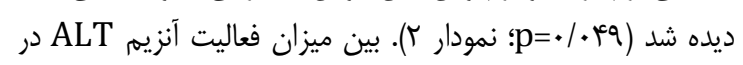

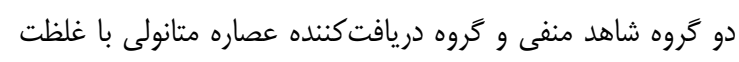

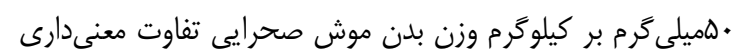

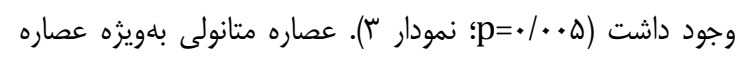

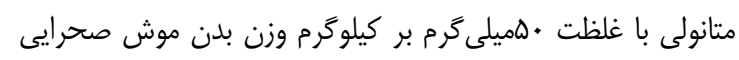

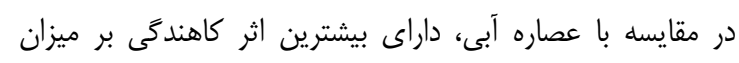

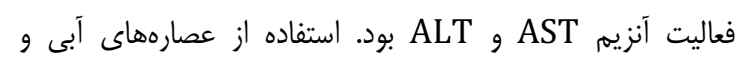

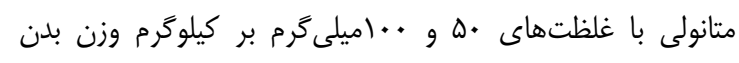

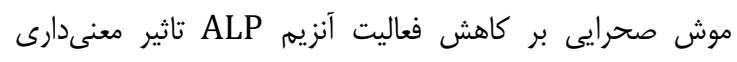

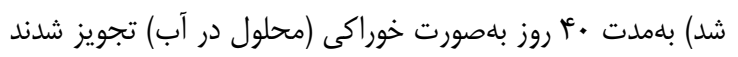

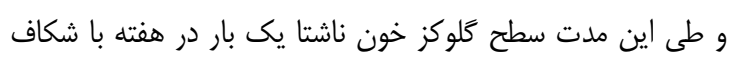

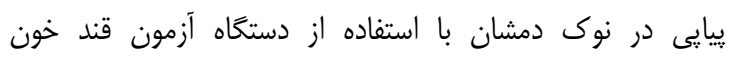

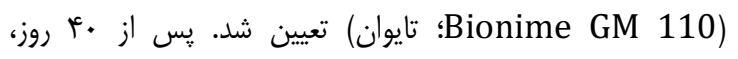

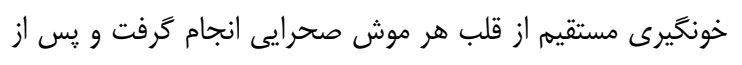

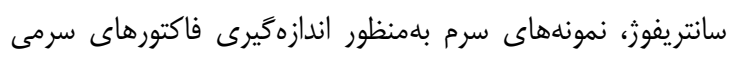

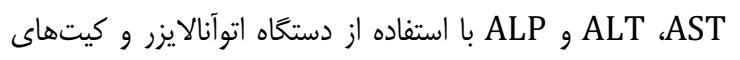

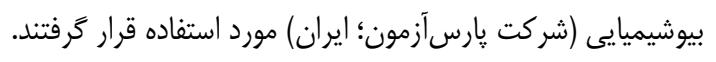

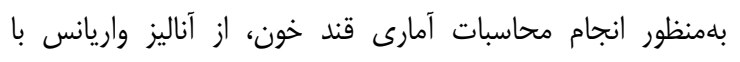

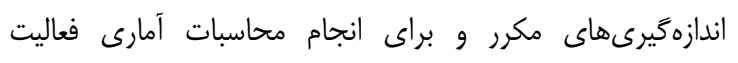

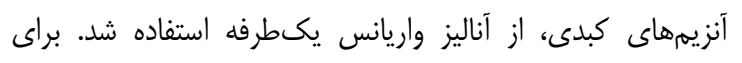

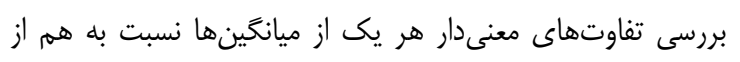

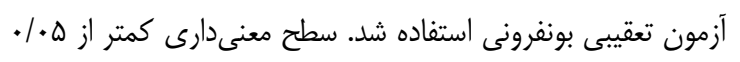

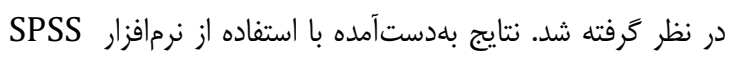

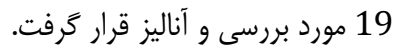

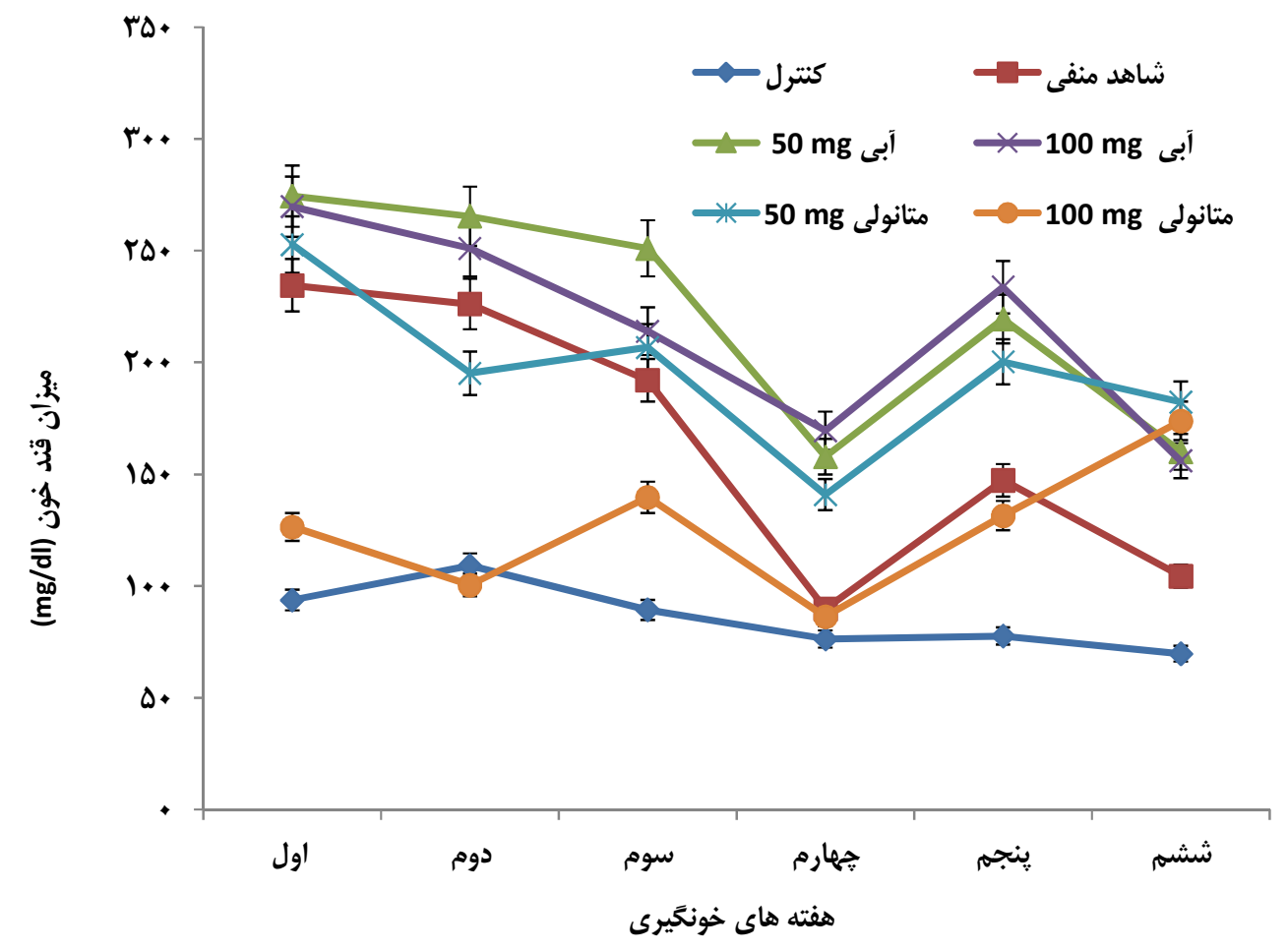

نمودار () تاثير غلظتهاى مختلف عصارههاى آبى و متانولى كار لا بر ميزان قند خون در گروههاى مورد آزمايش 

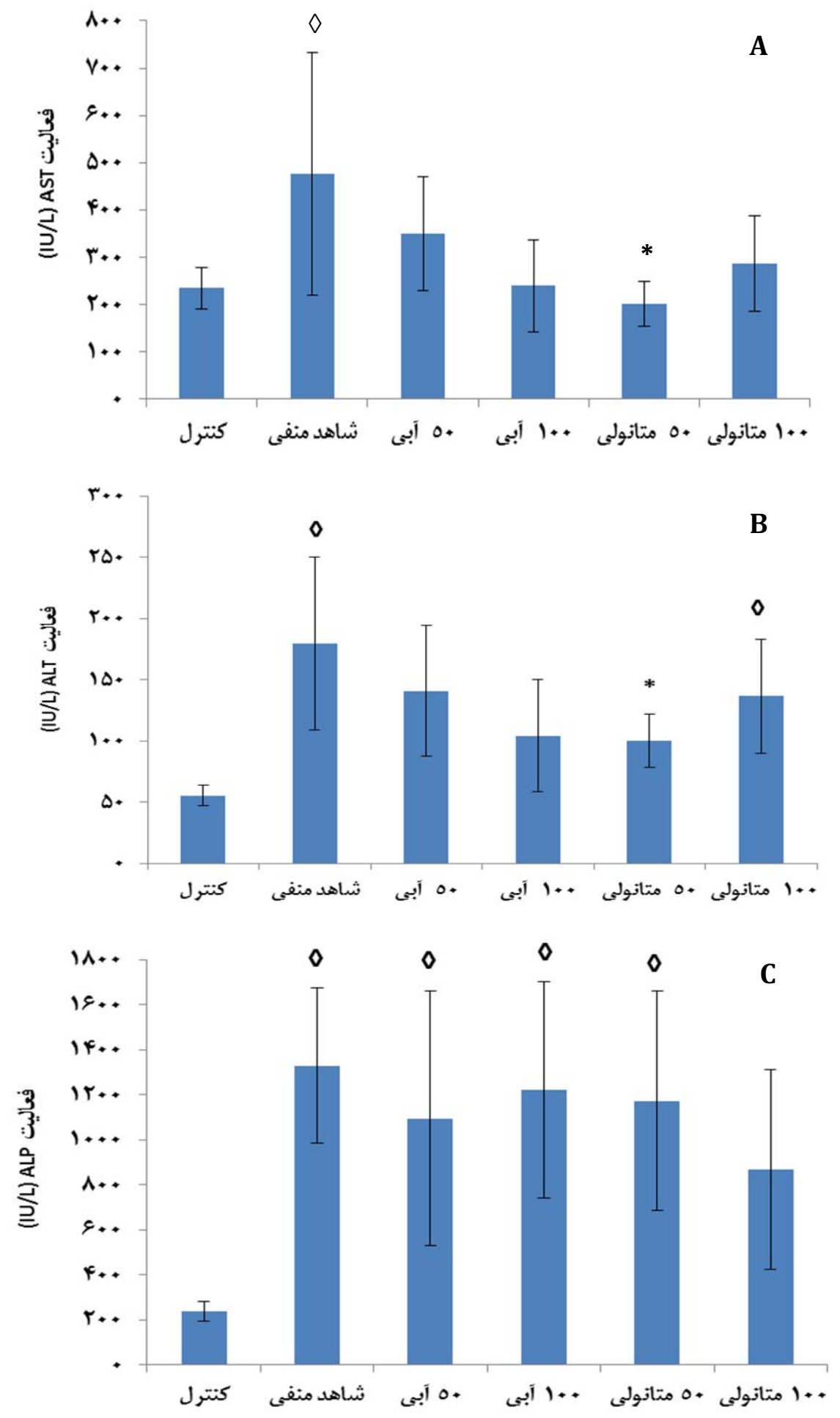

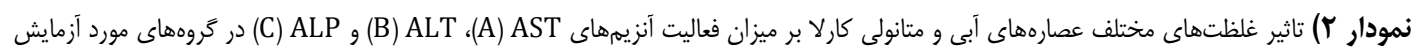

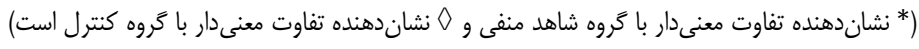




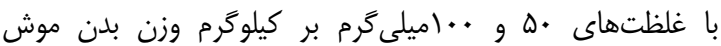

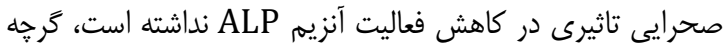

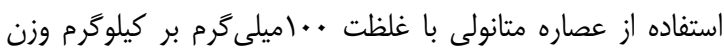

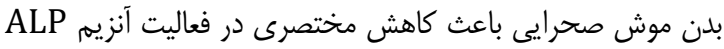

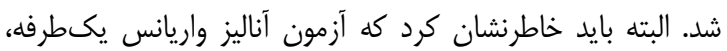

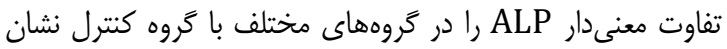

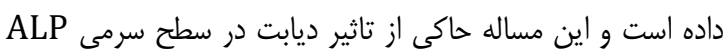

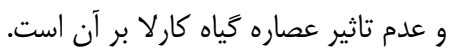

كزارشات حاكى از آن است كه ازدياد سطح موشهاى صحرايى ديابتىشده به تجمع زياد اسيدهاى آمينه

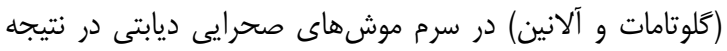

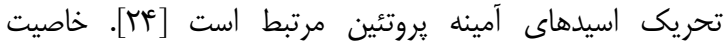

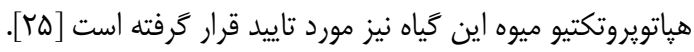
طبق كزارشات بلهدستآمده، فراكسيونهاى مختلف (يتروليوماتر،

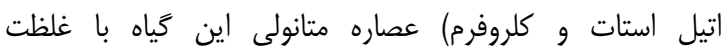
•هاميلى گرم بر كيلوَّرم وزن بلن موش صحرايى سبب كاهش

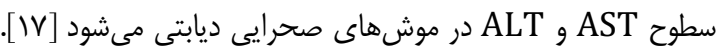

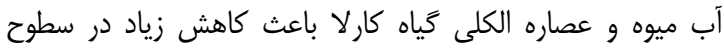

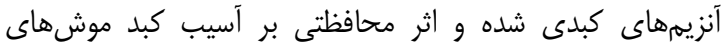
صحرايى درمانشده ديابتى داشته است [عبى].

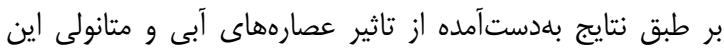

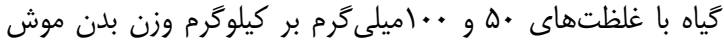

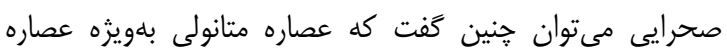
متانولى با غلظت كمتر اثر بهترى بر تنظيم فعاليت آنزيمهاى كبر كبدى

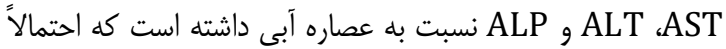
به اين دليل است كه تركيباتى از اين كياه كه در تنظيم فعاليت آنزيمهاى كبدى AST، ALT و ALP موثر هستند، توسط متانول

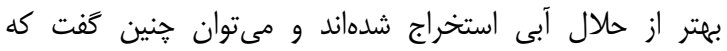

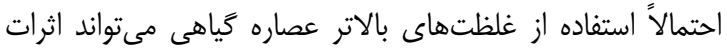

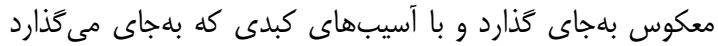

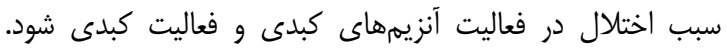

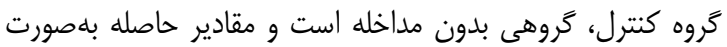

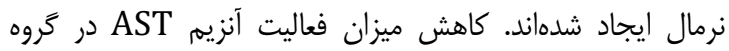

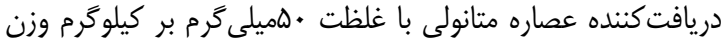

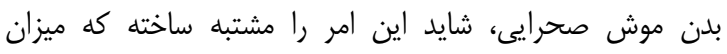

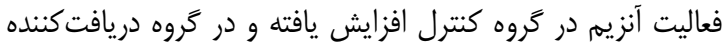

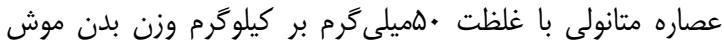
صحر ايى، شايد آسيب كبدى سبب كاهش ساخت آنزيم AST شده باشد. از محدوديتهاى اين مطالعه مىتوان به كمبود ميزان كياه در دسترس و تعداد موشهاى مورد مطالعه اشاره كرد. با توجه به اثرات آنهات
در اين تحقيق مشاهده شد كه متعاقب تجويز غلظتهاى مختلف

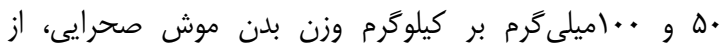

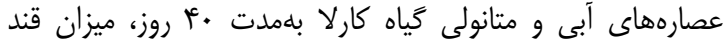

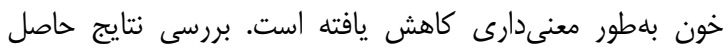

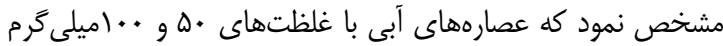

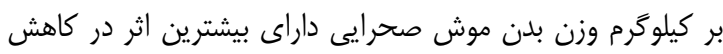

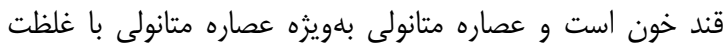

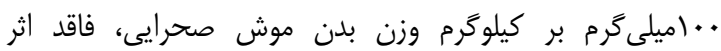
كاهندكى در قند خون است.

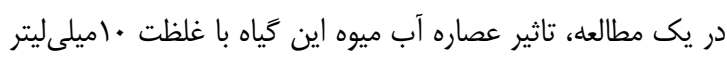
بر كيلوكرم وزن بدن موش صحرايى طى دوره بكاروزه در كاهش

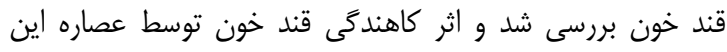

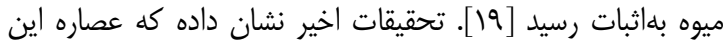

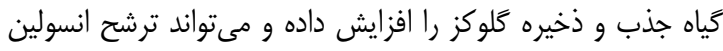

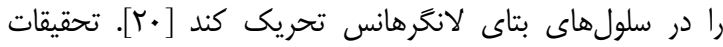

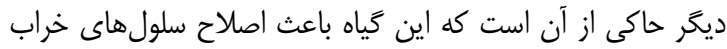

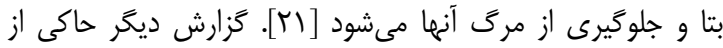

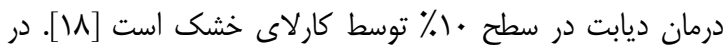

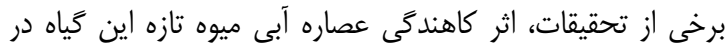

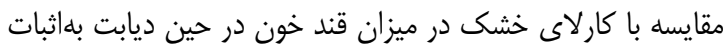

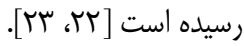

با توجه به نتايج بهدستآمده در اين تحقيق مبنى بر اينكه عصاره

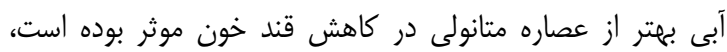
مىتوان جنين نتيجه كَرفت كه تركيباتى از اين كَياه كه در كاهش

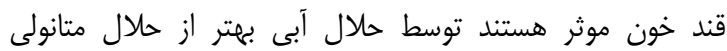

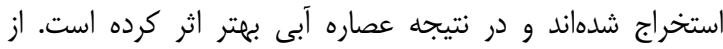

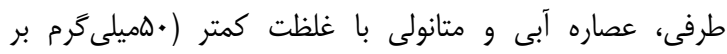

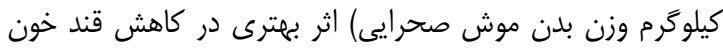

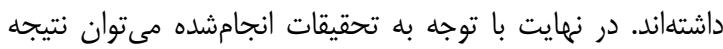

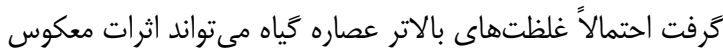
بهجاى كذاشته و عصاره با غلظت بيشتر سبب افزايش قنائ خائ خون شود. بررسى نتايج حاصل مشخص نمود كه عصاره متانولى اين

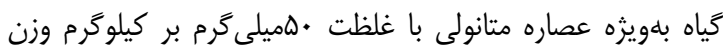

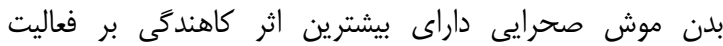
آنزيمهاى كبدى AST و ALT است و اين مساله نشان دهنده اثر ئر مطلوب عصاره متانولى با غلظت •هميلى كرم بر كيلوكرم وزن بدان

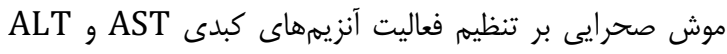

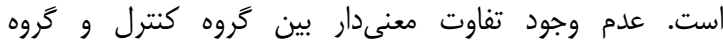

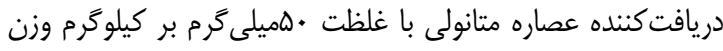
بدن موش صحرايى مجدداً نشاندهنده اثر تنظيمكننده اين غلظت

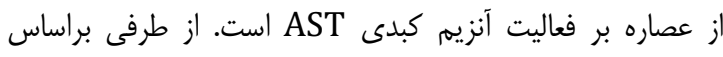
دوره آr، شماره r، تابستان IrqF فصلنامه افق دانش 
III تاثير عصاره آبى و متانولى ميوه كار لا (هندوانه تلخ) بر ميزان فند خون و آنزيمهاى كبدى در موشهاى صحرايى ديابتى

8- Xing Jiu H, Yang Kyn C, Hyung Soon I, Oktay Y, Euisik Y, Hak Sung $\mathrm{K}$, et al. Aspartate aminotransferase (AST/GOT) and alanine aminotransferase (ALT/GPT) detection techniques. Sensors. 2006;6(7):756-82.

9- Praff DS, Kaplan MM. Evaluation of abnormal liverenzyme results in asymptomatic patients. $\mathrm{N}$ Engl J Med. 2000;342(17):1266-71.

10- Joseph B, Jini D. Antidiabetic effects of Momordica charantia (bitter melon) and its medicinal potency. Asian Pac J Trop Dis. 2013;3(2):93-102.

11- Sarkar S, Pranava M, Marita R. Demonstration of the hypoglycemic action of Momordica charantia in a validated animal model of diabetes. Pharmacol Res. 1996;33(1):1-4.

12- Ananya P, Sarmistha SR. Medicinal uses and molecular identification of two Momordica charantia varieties: A review. EJBI0. 2010;6(2):43-51.

13- Chaudhari BP, Chaware VJ, Joshi YR, Biyani KR. Hepatoprotective activity of hydroalcoholic extract of Momordica charantia linn. leaves against carbon tetra chloride induced hepatopathy in rats. Int J Chem Tech Res. 2009;1(2):355-8.

14- Venkatesh S, Reddy GD, Reddy BM, Ramesh M, Rao AV. Antihyperglycemic activity of caralluma attenuata. Fitoterapia. 2003;74(3):274-9.

15- Zareba G, Serradell R, Castaner R, Davies SL, Prous J, Mealy N. Phytotherapies for diabetes. Drugs Future. 2005;30:1253-82.

16- Abdollahi M, Zuki ABZ, Goh YM, Rezaeizadeh A, Noordin MM. The effects of Momordica charantia on the liver in streptozotocin-induced diabetes in neonatal rats. Afr J Biotechnol. 2010;9(31):5004-12.

17- Hossain MS, Ahmed M, Islam A. Hypolipidemic and hepatoprotective effects of different fractions of methanolic extract of Momordica charantia (LINN.) in alloxan induced diabetic rats. Int J Pharm Sci Res. 2011;2(3):601-7.

18- Shetty AK, Kumar GS, Sambaiah K, Salimath PV. Effect of bitter gourd (Momordica charantia) on glycaemic status in streptozotocin induced diabetic rats. Plant Foods Hum Nutr. 2005;60(3):109-12.

19- Matheka DM ,Kiama TN, Alkizim FO, Bakachi F. Glucose-lowering effects of Momordica charantia in healthy rats. Afr J Diabets Med. 2011;19(2):15-9.

20- Leatherdale BA, Panesar RK, Singh G, Atkins TW, Bailey CJ, Bignell AH. Improvement in glucose tolerance due to Momordica charantia (karela). Br Med J. 1981;282(6279):1823-4.

21- Ahmed I, Adeghate E, Sharma AK, Pallot DJ, Singh J. Effects of Momordica charantia fruit juice on islet morphology in the pancreas of the streptozotocindiabetic rat. Diabetes Res Clin Pract. 1998;40(3):145-51. 22- Karunanayake EH, Jeevathayaparan S, Tennekoon KH. Effect of Momordica charantia fruit juice on streptozotocin-induced diabetes in rats. J Ethnopharmacol. 1990;30(2):199-204.

23- Ahmed I, Adeghate E, Cummings E, Sharma AK, Singh J. Beneficial effects and mechanism of action of Momordica charantia juice in the treatment of streptozotocin-induced diabetes mellitus in rat. Mol Cell Biochem. 2004;261(1-2):63-70.

24- Colev V, Bădescu M, Păduraru I, Mândreci I, Bohotin C. The zinc-metabolic disorder relation in experimental diabetes mellitus. Rom J Intern Med. 1994;32(1):71-5.

25- Shibib BA, Khan LA, Rahman R. Hypoglycaemic activity of Coccinia indica and Momordica charantia in diabetic rats: Depression of the hepatic gluconeogenic

$$
\begin{aligned}
& \text { مفيد اين گياه، يِيشنهاد مىشود به بررسى گستردهتر اين گياه }
\end{aligned}
$$

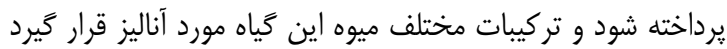

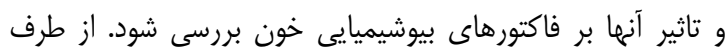

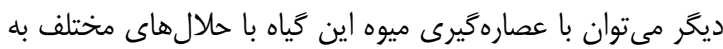

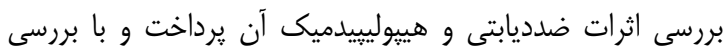

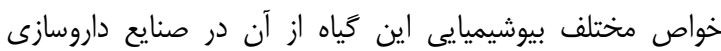

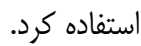

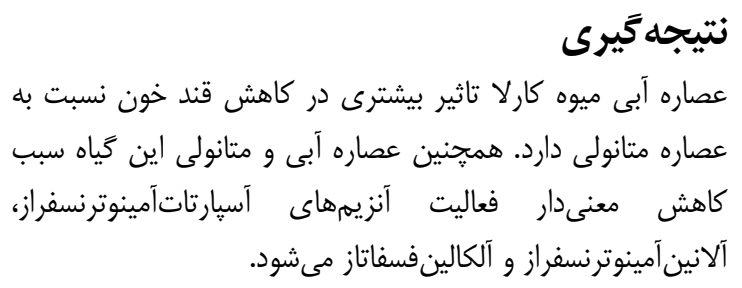

تشكر و قدردانى: از كاركنان آزمايشگاه تحقيقاتى دانشخاه آزاد

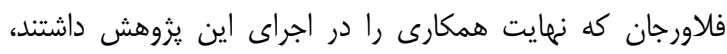
كمال تشكر و قدردانى بلعمل مى آيد.

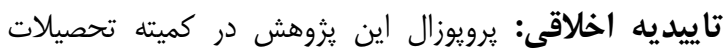

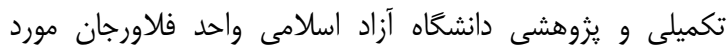
تصويب و تاييد اخلاقى قرار گرفت. تعارض منافع: موردى توسط نويسندكان گزارش نشده است. منابع مالى: بلهورت شخصى تامين شد.

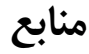

1- Fallah Huseini H, Fakhrzadeh H, Larijani B, Shikh Samani . Review of anti-diabetic medicinal plant used in traditional medicine. J Med Plants. 2006;1 Suppl 2:S1-8. 2- Srinivasan K, Ramarao P. Animal models in type 2 diabetes research: An overview. Indian J Med Res. 2007;125(3):451-72.

3- Matthaei S, Stumvoll M, Kellerer M, Häring HU. Pathophysiology and pharmacological treatment of insulin resistance. Endocr Rev. 2000;21(6):585-618.

4- Esteghamati A, Ashraf H, Khalilzadeh O, Rashidi A, Mohammad K, Asgari F, et al. Trends of diabetes according to body mass index levels in Iran: Results of the national surveys of risk factors of non-communicable diseases (1999-2007). Diabet Med. 2010;27(11):123340.

5- Hadaegh F, Bozorgmanesh MR, Ghasemi A, Harati H, Saadat N, Azizi F. High prevalence of undiagnosed diabetes and abnormal glucose tolerance in the Iranian urban population: Tehran lipid and glucose study. BMC Public Health. 2008;8:176.

6- Gilbert MP, Pratley RE. Efficacy and safety of incretinbased therapies in patients with type 2 diabetes mellitus. Am J Med. 2009;122 Suppl 2:S11-24.

7- Marles RJ, Farnsworth NR. Antidiabetic plants and their active constituents. Phytomedicine. 1995;2(2):13789. 
26- Abd El Sattar El Batran S, El Gengaihi SE, El Shabrawy OA. Some toxicological studies of Momordica charantia L. on albino rats in normal and alloxan diabetic rats. J Ethnopharmacol. 2006;108(2):236-42. enzymes glucose-6-phosphatase and fructose-1,6bisphosphatase and elevation of both liver and red-cell shunt enzyme glucose-6-phosphate dehydrogenase. Biochem J. 1993;292(Pt 1):267-70. 